\title{
Analysis of TMJ Vibration Sounds Before and After Use of Two Types of Occlusal Splints
}

\author{
Marcelo Oliveira MAZZETTO ${ }^{1}$ \\ Takami Hirono HOTTA ${ }^{1}$ \\ Rafaela Galli MAZZETTO² \\ ${ }^{1}$ Department of Restorative Dentistry, Ribeirão Preto Dental School, University of São Paulo, Ribeirão Preto, SP, Brazil \\ ${ }^{2}$ Dental School, University of Ribeirão Preto, Ribeirão Preto, SP, Brazil
}

\begin{abstract}
Temporomandibular joint (TMJ) sounds are important and common physical signs of temporomandibular disorders (TMD). The aim of this study was to evaluate the influence of the effect of the use of occlusal bite splints (stabilizing and repositioning) on the sounds produced in the TMJ, by means of the electrovibratography (EVG). Thirty-one patients with TMD from the Dental School of Ribeirão Preto, University of São Paulo, Brazil were selected for this study. Group $1(\mathrm{n}=23)$ wore stabilizing bite splints and Group 2 ( $\mathrm{n}=8$ ) used anterior repositioning splints. Before and after treatment with occlusal splints both groups were analyzed using the SonoPAK Q/S recording system (BioResearch System, Inc.). The treatments with stabilizing bite splints were satisfactory, since they reduced the total amount of the sound energies $(\mathrm{p}<0.05)$, but the use of anterior repositioning splints for no more than 4 weeks produced significantly better results $(\mathrm{p}<0.01)$. The total amount of vibration energy involved in the vibrating movements of the TMJ showed significant improvement using anterior repositioning splints.
\end{abstract}

Key Words: TMJ sounds, electrovibratography, occlusal splint.

\section{INTRODUCTION}

The recording of temporomandibular joint (TMJ) sounds is an important tool for the diagnosis and clinical examination of patients in whom internal derangements of joints are suspected. The electronic recording of sounds and vibrations in the TMJ allow for a detailed analysis and provide a more reliable comparison between different examiners and also between different sessions of clinical examinations (1).

Temporomandibular disorders (TMD) have deserve considerable research since patients present clinical characteristics of limited mouth opening, masticatory muscle spasms, internal derangement in the joints, and consequent instability of the disc-condyle complex producing articular sounds. According some authors, intra-articular sounds are universally accepted signs of TMD and they have correlated types of vibrations with specific disorders (2), although these signs also manifest in asymptomatic subjects (3).
The SonoPAK Q/S recording system (BioResearch System, Inc., Milwaukee, WI) is capable to record bilateral sounds of the TMJ in conjunction with mandibular movements, displaying noise intensity, frequency, duration and its exact occurrence during opening and/or closing jaw movements.

The evaluation of articular sounds is considered a key procedure and should be included as a criterion for the diagnosis of TMD. Specific parameters pondered in these diagnostic criteria consider the repetitive nature of the articular sounds; mandibular position during opening and closing; specific relationship of the sounds during the mandibular displacement; and movement's evaluation which may be moderate, with or without crepitus (4).

It has been shown that TMJ sounds (clicking, tripping noises and crepitus) are indication of various clinical conditions $(1,3,5,6)$. Some of these sounds indicate severe dysfunction needing immediate treatment. After a certain period of time, some sounds (and subjacent conditions) remain constant, while others tend 
to worsen progressively, and the best therapy advocated by professionals treating TMD is the prescription of occlusal bite splints (stabilization or repositioning types), due to their characteristics of being conservative, noninvasive and producing relatively satisfactory results.

The aim of this study was to evaluate the effect of the using occlusal bite splints (stabilizing and repositioning) on the sounds produced in the TMJ, by means of the electrovibratography (EVG).

\section{MATERIAL AND METHODS}

Thirty patients ( 2 males and 29 females) aged 17 to 67 years (mean age $=33.3$ years) were selected from the Dental School of Ribeirão Preto, University of São Paulo, Brazil, for this study. The clinical examination included a detailed questionnaire providing information on the patient's general health status, auscultation with stethoscopes to reveal TMJ sounds, and assessment of the presence of an asymmetric trajectory of the mandible during mouth opening/closure and lateral movement deviation to the affected articular side. The presence and location of pain were also verified because these may affect the range of mandibular movements. All patients underwent EVG protocol to obtain their classification into the articular dysfunction.

The patients in Group $1(\mathrm{n}=23)$ had articular disc derangement and wore stabilizing bite splints, while the patients in Group $2(\mathrm{n}=8)$ had anterior disk displacement with reduction and used anterior repositioning splints. Both types of occlusal splint were indicated because the clinical examination suggested the occurrence of anterior disk displacement with reduction. The reduction of disk displacement occurred when the patients were asked to open their mouth from the edge to edge position of the anterior teeth. The EVG analysis of all 31 patients was done before and after treatment to determine the effect of the occlusal bite splints on the internal derangements of the TMJ. The patients were fully informed about the therapy and signed a written consent form approved by the Ethics Committee of the Dental School of Ribeirão Preto, University of São Paulo (Process \# 2006.1.559.58.7).

The recordings were made with the patients seated in a padded chair in a comfortable position and facing a computer monitor loaded with the SonoPAK Q/S program (BioResearch System), which was ready to collect the sounds produced by the joints. The am- plifier was hanging from the patients' neck and resting on their chests. Sensors (Piezoelectric accelerometers) were adapted on the facial skin, which was previously cleaned with alcohol sponges, at the level of the lateral poles of the condyles. Opening and closing movements of the mouth were imparted and digital palpation was utilized to help in the location of the lateral poles (7). The sensors were adapted at the level of these poles. The right lead (red color) and the left lead (blue color) of each sensor were connected to the amplifier.

To initiate the joint vibration analysis (JVA), personal data of each patient were taken as well as measurement of the maximum mouth opening (including overbite) and observation of possible lateral deflection of the mandible during the opening movement. All measurements were recorded in millimeters in the computer program window. The patient was instructed to look at the monitor and start making opening and closing movements of the mouth. The movements were guided by an arrow in the metronome screen. The arrow pointing downwards was for the patient to produce a maximum opening and the arrow pointing upwards was for the patient to produce closing movement with a forceful bite. The patient was trained for 2 to $3 \mathrm{~min}$, always observing the arrows in the monitor screen.

A few minutes after the training period, the patient started the opening and closing movements of the jaw, according to the procedures described above. Recordings were made and properly saved, if they were acceptable. For each patient, all recordings were collected before the insertion of the splints and 4 weeks later after the use of each type of splint.

It was possible to record 6 separate vibrations simultaneously using color schemes on the computer screen. The sounds were successively recorded and any occlusal contact was disregarded due to the production of undesirable occlusal contact's sounds. After recording of the sounds, the program showed the JVA summary for the entire sample and the amount of the vibration energy occurring in each TMJ (integral total). When multiple vibrations were recorded, it was important to define the corresponding type of analogous vibration during each cycle of opening or closing of the jaw, since the purpose of our analysis was to study the mean of all vibrations.

\section{RESULTS AND DISCUSSION}

The experimental data in this study consisted of 
a group of 92 numerical data referring to the amount of total energy of the TMJ vibrations of patients before and after treatment with occlusal splints, calculated from the JVA summary, which was calculated by the use of the SonoPAK Q/S (BioResearch System) in the right and left joints.

Data referred to measurement of articular sounds, calculated by EVG are presented in Table 1. These data expressed the raw values of the energy produced during the vibrating movements of the right and left TMJ of the patients of group 1, before starting the treatment and after being submitted to treatment with stabilizing bite splints. The total number of sample data resulted from the factorial product of 2 types of treatments, 2 sides and 23 patients (repetitions) $(2 \times 2 \times 23=92$ sample data $)$.

The preliminary tests demonstrated that the distribution of the experimental data was normal and the samples homogeneous enough to allow for the application of parametric tests. From all tests, the one most adaptable to the mathematical model of the experiment was the mixed analysis of variance factors, containing 2 non-independent variables (before and after treatment with bite splint, and 2 TMJ sides). In fact, it consisted of a single analysis, with 2 variable factors and 23 patients (repetitions).

The results showed statistically significant difference $(p<0.05)$ between the results obtained before and after the treatment with bite splints, whereas no significant differences $(p>0.05)$ were found between the right and left TMJs.

Another important finding of this study was the great variability among the individuals composing the sample $(p<0.01)$. This made necessary to isolate the variable patients, since the inclusion of this variable in the residue would inflate greatly the experimental error, confusing and making more difficult any interpretation of the results. On the other hand, the interactions between the 2 variable were not significant.

In order to determine which of the measurements involved in the analysis of variances were significantly different from each other, a complementary Tukey's test was performed for each variable.

There was statistically significant difference $(p<0.05)$ between patients who used (38.09) and did not use stabilizing bite splint (29.54). The use of the stabilizing bite splint was able to reduce the total vibration energy produced in the TMJ. The truth of this statement may be readily ascertained when referring to authors that recommend the use of occlusal bite splints for the treatment of internal joint derangement, aiming the reduction of TMJ sounds (8). In addition, the use of splints is a controversial subject when applied for TMJ clicking (9), situation in which the repositioning appliance can produce better results (10). Regarding the side (right or left), when comparing the corresponding

Table 1. Means of the total energy generated during vibration movements of the left and right temporomandibular joints (TMJs) in Group 1's patients before and after treatment with stabilizing bite splints (Pascal).

\begin{tabular}{|c|c|c|c|c|}
\hline \multirow{2}{*}{ Patients } & \multicolumn{2}{|c|}{ With occlusal splint } & \multicolumn{2}{|c|}{ Without occlusal splint } \\
\hline & Left TMJ & Right TMJ & Patients & Left TMJ \\
\hline 1 & 11.7 & 9.3 & 18.8 & 12.6 \\
\hline 2 & 5.0 & 5.9 & 10.3 & 7.3 \\
\hline 3 & 17.0 & 55.4 & 10.4 & 20.2 \\
\hline 4 & 25.9 & 7.6 & 16.6 & 7.3 \\
\hline 5 & 90.7 & 87.9 & 37.1 & 20.7 \\
\hline 6 & 227.5 & 150.9 & 265.2 & 140.5 \\
\hline 7 & 14.9 & 15.6 & 12.8 & 16.0 \\
\hline 8 & 28.4 & 11.1 & 39.9 & 12.1 \\
\hline 9 & 33.4 & 11.2 & 22.3 & 19.6 \\
\hline 10 & 10.1 & 13.7 & 13.6 & 12.6 \\
\hline 11 & 77.9 & 81.4 & 54.1 & 74.9 \\
\hline 12 & 92.3 & 19.3 & 67.3 & 18.2 \\
\hline 13 & 15.3 & 18.5 & 11.9 & 12.1 \\
\hline 14 & 10.4 & 32.9 & 12.2 & 23.1 \\
\hline 15 & 10.8 & 46.2 & 14.3 & 38.8 \\
\hline 16 & 67.1 & 35.6 & 51.8 & 13.1 \\
\hline 17 & 21.3 & 34.4 & 18.3 & 33.6 \\
\hline 18 & 31.0 & 36.6 & 5.4 & 13.5 \\
\hline 19 & 26.2 & 17.9 & 16.2 & 11.3 \\
\hline 20 & 14.1 & 13.7 & 5.2 & 4.4 \\
\hline 21 & 16.7 & 59.0 & 16.3 & 9.8 \\
\hline 22 & 110.4 & 48.3 & 63.2 & 17.1 \\
\hline 23 & 20.5 & 13.9 & 20.4 & 16.6 \\
\hline Mean & 42.56 & 34.94 & 33.62 & 24.15 \\
\hline
\end{tabular}


measurements between each other, the observed numerical differences did not show any amount of difference. These findings proved, with absolute degree of certainty, that they were statistically similar. In other words, the difference between the mean values displayed simply the same magnitude as the experimental error, which may be present in any research project. Still regarding the sides, there was no statistically significant difference between the right (28.88) and the left (38.75) TMJs, suggesting that this factor was not influenced by the analysis of sound vibration when occlusal stabilizing splints were used for patients with TMD (11).

The lack of statistically significant differences (pointed out by the analysis of the variance of all interactions between the 2 variable factors studied) demonstrated that the factors before and after use of the occlusal bite splint were similar to the experimental error, in spite of showing numerical variations between one side and the other of the patients. As for example, the comparison of the means, when each side of the patients was considered as a group, demonstrated that before and after treatment there was a tendency to show differences in an increasing order (right side with splint 24.15; right side without splint 34.94; left side with splint 33.62; and left side without splint 42.56 , respectively). Table 1 shows that the use of the occlusal splint reduced bilateral TMJ sounds of the patients. However, the statistical analysis demonstrated that these differences were irrelevant,

Table 2. Means of the total energy generated during vibration movements of the left and right temporomandibular joints (TMJs) in Group 2's patients before and treatment with the anterior repositioning appliance (Pascal).

\begin{tabular}{crrrrr}
\hline \multirow{2}{*}{ Patients } & \multicolumn{2}{c}{ With occlusal splint } & & \multicolumn{2}{c}{ Without occlusal splint } \\
\cline { 2 - 3 } \cline { 5 - 6 } & Left TMJ & Right TMJ & & Left TMJ & Right TMJ \\
\hline 1 & 224.5 & 334.5 & & 24.9 & 47.4 \\
2 & 116.8 & 225.7 & & 11.4 & 30.0 \\
3 & 27.1 & 40.0 & & 9.4 & 9.0 \\
4 & 146.7 & 50.9 & & 93.0 & 55.9 \\
5 & 138.9 & 55.6 & & 58.5 & 36.5 \\
6 & 26.7 & 118.2 & & 44.9 & 14.0 \\
7 & 162.1 & 37.9 & & 55.9 & 15.4 \\
8 & 95.0 & 90.9 & & 6.6 & 8.0 \\
Mean & 117.22 & 119.21 & & 38.70 & 27.04 \\
\hline
\end{tabular}

taking into consideration variations resulting from the experimental error. Likewise, results from treatments seem to depend more likely on some particular aspect related to each patient rather than to the body's side.

Data referring to the measurement of articular sounds as measured by EVG are presented in Table 2, which expresses the raw data of the mean total energy produced during vibration movements of left and right TMJ, before and after treatment with repositioning appliances. The total number of data is the result of the factorial product of 2 treatments, 2 sides and 8 patients (repetitions) $(2 \times 2 \times 8=32$ sample data).

Preliminary tests demonstrated that the distribution of the experimental data was normal and the sample homogenous enough to utilize parametric tests. From all these tests, the one most adaptable to the mathematical model of the experiment was the mixed analysis of the variance, containing 2 non-independent variables (before and after use of repositioning appliances, left and right TMJ). In fact, it consisted of a single analysis, with 2 variable factors and 8 patients (repetitions).

The results showed the highly statistical significance $(p<0.01)$ between before treatment and after treatment with the anterior repositioning, whereas there were no statistically significant differences to the variable factor sides (left or right TMJ). Probably, these results occurred due the anterior repositioning splint is the most accepted treatment for anterior disk displacement with reduction (12).

Regarding the variable treatment, a significant difference $(\mathrm{p}<0.01)$ was detected. Analysis of this factor was able to show enough amounts of numerical differences to warrant, with absolute certainty, that the results are statistically different between each other. After the application of the Tukey's test it was concluded that the utilization of the repositioning appliance reduced the sounds in the TMJ $(p<0.01)$, independently of the variable factor sides. Therefore, when comparing the results of the total vibration energy, measured by EVG, in patients before (118.21) and after the use anterior repositioning appliance (32.87), it was possible to note that this highly statistically significant difference may indicate the use of these appliances to eliminate sounds in the joints, mainly referred to stages I and II, as reported by studies (12-16).

However, as related to the variable factor side, the statistical analysis did not demonstrate any 
significant difference between the means for the left side (77.96) and right side (73.12). Therefore, it was revealed a total integral mean of vibrations similar for both sides.

The lack of statistically significant differences (pointed out by the analysis of the variance of all interactions between the 2 variable factors studied) demonstrated that the factors before and after the use of the repositioning appliance, although showing numerical variations between one side and the other of the patients, were similar to the experimental error. For example, the comparison of the means, when each side of the patients was considered as a group, revealed that before and after treatment there was a tendency to show differences in a crescent order (right side with appliance 27.04; right side without the appliance 117.22; left side with appliance 38.70; and left side without appliance 119.21). The use of the repositioning appliance reduced bilateral sounds in the patient's TMJ, when the 2 sides of the head were compared (Table 2). However, the statistical analysis uncovered that any difference was irrelevant, taking into consideration the variations resulting from experimental errors. It is important to stress that this study represents a short-term evaluation where positive results were obtained with the use of anterior repositioning appliances. Garcia et al. (13) also observed the decreasing of vibrations when the mandible was advanced by the interoclusal device. They suggested that this situation may produce the reduction of the disk. However, no longterm evaluations were obtained at this time, when both types of appliances used in this project were considered. In the present study, the authors selected these appliances due they had been referred by others researchers although the existence of many controversial opinions about their effects $(9,10,17-19)$.

As a final remark, it is important to mention that limitations of this study include the small number of patients that were available for treatment with repositioning devices. Repetitive measurements should have been used during longer period of time (months), until any device can be considered satisfactory for the treatment. This study will be complemented by another one which will use a larger sample and longer period of time for control of the results although, according Garcia et al. (12) have shown success on the treatment of TMJ sounds with these types of the occlusal splints $(18,19)$.

At the moment that the disk is replaced on the condyle, locking disappears and sound energy is released in the form of clicking high vibratory intensity and with the use of an occlusal splint, the means of vibratory intensities decrease, probably due the amount of the separation between the dental arches produced by this interocclusal device, which could cause a forward rotation of the condyle favoring its recapture partially or permitting a softer movement during its replacement (12).

Considering the use of the occlusal splints as efficient device to TMD signs and symptoms, in the present study, the authors verified a decrease of the vibratory energy after use of these devices. It may be related to the results of the earlier study (20) in which the asymptomatic group registered lower values of the vibratory energy when compared to the averages of the symptomatic group.

By using these parameters of TMJ vibration energy analysis, a separation may be made between patients with normal joint anatomy and internal derangement and it also serves to analyze the efficiency of a selected treatment.

Based on the results of this study using EVG of patients with TMD, during and after treatment using occlusal splints, and considering the experimental conditions and methods utilized in this project, it was possible to conclude that: the total amount of vibration energy involved in the vibrating movements of the TMJ, showed significant improvement using anterior repositioning appliances; the repositioning appliances, showed the best performance, as they reduced the sound levels in the TMJ $(p<0.01)$ independent of the variable factor side; the variable factor side (left or right joint) did not change any of the variables tested; interactions between the variable factors treatments and sides were also not influenced by the variables tested.

\section{RESUMO}

Os ruídos da articulação temporomandibular (ATM) são sinais físicos importantes e comuns da disfunção temporomandibular (DTM). O objetivo do presente estudo foi avaliar o efeito do uso da placa oclusal (estabilizadora e reposicionadora) nos sons produzidos na ATM, por meio da eletrovibratografia (EVG). Um total de 31 pacientes da Faculdade de Odontologia de Ribeirão Preto - USP foram selecionados para este estudo. O grupo 1 $(n=23)$ foi selecionado para usar a placa estabilizadora e o grupo $2(\mathrm{n}=8)$ para usar a placa reposicionadora. Antes e depois do uso das placas os grupos foram analisados usando o SonoPAK Q/S (BioResearch System). Os tratamentos com placas estabilizadoras foram satisfatórios quando analisados estatisticamente uma vez que reduziram a quantidade total de energia dos sons $(p<0,05)$. O tratamento com placa reposicionadora, por 4 semanas no máximo, 
produziu melhores resultados estatísticos $(\mathrm{p}<0,01)$. A quantidade total de energia de vibração nos movimentos vibratórios da ATM mostrou significante melhora usando a placa reposicionadora.

\section{REFERENCES}

1. Oster C, Katzberg R, Tallents R, Morris T, Bartholomew J, Mueller T, et al.. Characteristics of temporomandibular joint sounds. Oral Surg Oral Med Oral Pathol 1984;58:10-16.

2. Bassette RW. A clinical study of temporomandibular joint vibration in TMJ dysfunction studies. In: American Academy of Head, Neck, Facial Pain and TMJ Orthopedics. Kansas City: Anals 1992.

3. Deng M, Long X, Dong H, Chen Y, Li X. Electrosonographic characteristics of sounds from temporomandibular joint disc replacement. Int J Oral Maxillofac Surg 2006;35:456-460.

4. American Academy of Craniomandibular Disorders. Guidelines for Evaluation, Diagnosis and Management. Quintessence Publ.;1990.

5. Tallents RH, Hatala M, Katzberg RW, Westesson PL. Temporomandibular joint sounds in asymptomatic volunteers. J Prosthet Dent 1993;69:298-304.

6. Gay T, Bertolami CN, Donoff RB, Keith DA, Kelly JP. The acoustical characteristics of the normal and abnormal temporomandibular joint: diagnostic implications. J Oral Maxillofac Surg 1987;45:397-407.

7. Kecik D, Kocadereli I, Saatci I. Condylar disc relationships and vibration energy in asymptomatic class I 9 to 12 -year old. Angle Orthod 2005;75:54-62.

8. Okeson JP. Management of temporomandibular disorders and occlusion. Okeson JP (Editor). 5th. ed. St. Louis: Mosby Year-Book; 2003.

9. Wassel RW, Adams N, Kelly PJ. The treatment of temporomandibular disorders with stabilizing splints in general dental practice: one-year follow-up. J Am Dent Assoc 2006;137:1089-1098.

10. Kurita H, Ohtsuka A, Kurashima K, Kopp SL. A study of factors for successful splint capture of anteriorly displaced temporoman- dibular joint disc with disc repositioning appliance. J Oral Rehabil 2001;28:651-657.

11. Schmitter M, Zahran M, Duc JM, Henschel V, Rammelsberg P. Conservative therapy in patients with anterior disc displacement without reduction using 2 common splints: a randomized clinical trial. J Oral Maxillofac Surg 2005;63:1295-1303.

12. Garcia AR, Folli S, Zuim PRJ, Sousa V. Mandible protrusion and decrease of TMJ sounds: an electrovibratographic examination. Braz Dent J 2008;19:77-82.

13. Major P, Nebbe B. Use and effectiveness of splint appliance therapy: review of the literature. J Craniomandib Pract 1997;15:159166.

14. Sato H, Fujii T, Uetani M, Kitamori H. Anterior mandibular reposition in a patient with temporomandibular disorder: a clinical and tomography follow-up. Case report. J Craniomandib Pract 1997; $15: 84-88$

15. Summer JD, Westesson P. Mandibular repositioning can be effective in treatment of reducing TMJ disk displacement. A long-term clinical and magnetic ressonance imaging follow-up. J Craniomandib Pract 1997;15:107-120.

16. Mazzetto MO, Hotta TH, Carrasco TG, Mazzetto RG. Characteristics of TMD noise analyzed by electrovibratography. J Craniomandib Pract 2008;26:1-7.

17. Eberhard D, Bantleon HP, Steger W. The efficacy of anterior repositioning splint therapy studied by magnetic resonance imaging. Eur J Orthod 2002;24:343-352.

18. Fayed MM, El-Mangoury NH, El-Bokle DN, Belal AI. Occlusal splint therapy and magnetic resonance imaging. World J Orthod 2004;5:133-140.

19. Kai S, Kai H, Tabata O, Tashiro H. The significance of posterior open bite after anterior repositioning splint therapy for anterior displaced disk of the temporomandibular joint. Cranio 1993;11:146152.

20. Olivieri KA, Garcia AR, Paiva G, Stevens C. Joint vibrations analysis in asymptomatic volunteers and symptomatic patients Cranio 1999; 17:176-183. 